\title{
COMPUTABLE GENERAL-EQUILIBRIUM MODELS AND MONETARY POLICY ADVICE
}

by David Altig, Charles T. Carlstrom, and

Kevin J. Lansing

David Altig is an assistant vice president and economist and Charles T. Carlstrom and Kevin J. Lansing are economists at the Federal Reserve Bank of Cleveland. For useful comments and suggestions, the authors thank Tim Fuerst, Bill Gavin, Eric Leeper, Ed Prescott, and seminar participants at the University of Rochester and at the October 1994 Federal Reserve System Committee Meeting on Business Conditions. This paper was presented at the Federal Reserve Bank of Cleveland's Conference on Liquidity, Monetary Policy, and Financial Intermediation, September 1994.

Working papers of the Federal Reserve Bank of Cleveland are preliminary materials circulated to stimulate discussion and critical comment. The views stated herein are those of the authors and not necessarily those of the Federal Reserve Bank of Cleveland or of the Board of Governors of the Federal Reserve System. 


\begin{abstract}
This paper argues that variations of extant general-equilibrium monetary models are capable of generating real-time economic forecasts comparable in accuracy to those generated under the standard Federal Reserve Board staff methodology. Specifically, we argue that over the 1984-1990 period, forecasts generated by versions of the "limited participation" models developed by Fuerst (1992) and Christiano and Eichenbaum (1992a, 1992b) compare favorably with those contained in the Board staff's "Greenbook" briefing documents. We conclude that further development of these models holds promise for fully integrating the forecasting and policy analysis elements of the Federal Reserve's monetary policy advice process.
\end{abstract}




\section{Introduction}

To a Fed economist, the "Greenbook" and "Bluebook" -- that is, the briefing materials provided by the Board of Governors' staff of economists for each meeting of the Federal Open Market Committee (FOMC) -- are among the raw materials of monetary policy advice. The independent research and modeling within the individual District banks notwithstanding, the analysis contained in each Greenbook and Bluebook constitutes the common focal point for FOMC-directed policy discussions throughout the Federal Reserve System.

Writing in the Autumn 1980 volume of the Carnegie-Rochester Conference Series on Public Policy, Raymond Lombra and Michael Moran provided the first widely available, documented glimpse of these most basic building blocks of U.S. monetary policy advice. ${ }^{1}$ They explain that

[the Greenbook] lays out the assumptions underlying the [staff's economic] forecast, particularly any changes in key assumptions ... ; sums up the net implication of data received since the last meeting; lays out the revised forecast for GNP, inflation, and unemployment; and explains any significant changes in the staff's economic outlook. (p. 13)

Of the Bluebook they write:

The Bluebook ... presents alternative short-run policy options for the FOMC's consideration, develops the relationship between each alternative and the longer-run monetary targets, and discusses the implications of each alternative for near-term financial developments. (p. 14)

In describing the technical context of the long-run policy analysis provided in the briefing process, the authors explain that

1 See Lombra and Moran (1980). There were, of course, many general descriptions of the FOMC decisionmaking process published prior to the Lombra and Moran paper (Poole [1975], for example). However, theirs is the first to our knowledge that exploited declassified briefing documents. 
inputs considered by the senior staff in developing the forecasts [include] projections from the staff's version of the MPS model, as well as judgmental projections developed with the aid of surveys, leading and lagging indicators, and other business cycle techniques ... In addition to the "no change in policy" forecast, there are supplemental forecasts based on alternative monetary policy and fiscal policy alternatives. The FOMC debates the various alternatives and selects a particular longer-run money growth target. (p. 12)

Because access to the contents of specific Bluebooks and Greenbooks is restricted for a period of five years subsequent to the FOMC meetings for which they are constructed, Lombra and Moran base their remarks on documentation from the period between 1970 and 1973. Thus, although these descriptions of staff briefing activities were published 15 years ago, they actually pertain to the policy advice routine as it existed some 20 years ago. Despite this fact, the Lombra and Moran portrayal of economic analysis as it impacts the FOMC decisionmaking process is anything but dated: With very few (and very minor) changes, Lombra and Moran describe current briefing procedures as aptly as they do those of two decades ago.

This inertia in the methodology of monetary policy advice stands in stark contrast to the enormous ferment in theoretical and empirical macroeconomics that has occurred over the same period. Although advances in macroeconomics have certainly influenced the basic research agendas of Fed economists -- and thus have significantly colored perceptions of the advice that is given -- they have had remarkably little influence on the nuts and bolts of generating ongoing policy analysis as it is actually practiced.

We attribute this to two widely held beliefs. The first is the opinion that policymakers (and, more broadly, the general public) have been reasonably well served by traditional practices, not least because the cumulative wisdom of economic theory is 
internalized into the policy advice process through the good judgment of the people who give it. The second is the sense that state-of-the-art quantitative-theoretic models, which by necessity are highly stylized and abstract, are not equal to the real-time task of, in the words of Lombra and Moran, "developing an overall, integrated assessment of economic and financial developments, laying out feasible policy alternatives for consideration by policymakers and making specific policy recommendations."

We have no quarrel with the tenor of this first belief: The sincere and professional efforts of succeeding generations of Federal Reserve staff economists have, in general, contributed in substantial and positive ways to the conduct of U.S. monetary policy. However, well served does not preclude better served. In particular, analysis built upon a foundation of "judgmental projections developed with the aid of surveys, leading and lagging indicators, and other business cycle techniques" is necessarily highly subjective and hence limits the level of explicitness at which the policy advice process is conducted. Furthermore, in practice, the staff's "current analysis" activities (the Greenbook exercise) are largely unrelated to explicit policy analysis activities (the Bluebook exercise).

Of course, these observations lack practical content unless we can plausibly suggest that results from more explicit frameworks can be brought to bear on the realtime data analysis required of the FOMC briefing process. A main theme of this paper is that it is indeed plausible that variations and extensions of extant quantitative-theoretic models -- which we will refer to as computable general-equilibrium (CGE) models -- are useful in the task of providing real-time forecasting inputs to policymakers. 
In supporting this assertion, we add to the recent work of Hansen and Prescott (1993) and Leeper and Sims (1994). As in Hansen and Prescott, our quantitative outcomes are generated from an explicit general-equilibrium model calibrated to match certain key characteristics of the data, à la Kydland and Prescott (1994). However, whereas Hansen and Prescott concentrate on tracing the simulated path of real variables using actual realizations of shocks to factor productivity (so-called technology shocks), we focus on short-term conditional forecasting of output and inflation, as in the Greenbook. In this regard, our experiments are closer in spirit to Leeper and Sims, who take up the issue of policy forecasting in the context of a theoretically restricted VAR. However, Leeper and Sims attempt to jointly estimate the parameters of their model's structure and exogenous stochastic processes from time-series data, in contrast to the simpler calibration methodology we apply in this paper.

The specific framework we employ is in the class of "limited participation" models described by Fuerst (1992) and Christiano (1991). We choose this theoretical structure as a logical starting point because it can generate outcomes that conform with common beliefs about monetary policy and its effects. For instance, the model exhibits neutrality of money growth in the long run (apart from inflation tax effects), short-run real output effects from monetary "surprises," and an inverse relationship between money supply surprises and nominal interest rates. In addition, our setup incorporates a centralbank reaction function that involves operating on a nominal interest-rate target, as in Carlstrom (1994) and Carlstrom and Fuerst (1994). A detailed description of our model is provided in section 2 . 
We argue that our results show that quantitative-theoretic models are capable of being called to the service of real-time forecasting. To be more specific, by the meansquared-error and mean-absolute-deviation metrics, the forecast errors of our chosen CGE models are comparable to those of the Greenbook projections over the 1984-1990 period that we study.

We do not claim to be presenting the definitive theoretically based forecasting framework. Parts of our analysis are "judgmental," in the sense that numerical outcomes are generated by using inputs that do not strictly arise from the theoretical structure of a well-defined calibration exercise. These issues are discussed in section 3 , along with the basic forecast results.

Additionally, although encouraged by the forecasting potential of the CGE modeling approach, we also emphasize a fundamental problem with integrating policy analysis into the version of the model presented here. To make this issue concrete, suppose that a policy regime can be cast as a simple Markov process for some policy variable $x$, given by $x_{t}=\lambda x_{t-1}+\eta_{t}$. In our analyses, this process would describe the Fed reaction function, where $x_{t}$ is the deviation of the nominal interest rate from its mean, $\lambda$ is the autoregressive coefficient in the interest-rate law of motion, and $\eta_{t}$ is a random shock to policy.

In the original sense of Lucas (1976), policy analysis corresponds to a change in $\lambda$. However, Leeper and Sims note that most real-time policy advice -- including that associated with the FOMC briefing and decisionmaking process -- is better characterized as an examination of alternative sequences of the random variables $\eta_{t+j}(j \geq 0)$, holding 
$\lambda$ fixed. Echoing a position staked out in Sims (1986), they further argue that such an approach is sensible, since the deviation from a strict rational-expectations construction implied by these experiments is unlikely to be crucial for short-run projections of alternative policies.

We find that the strategy proposed by Leeper and Sims is not successful in the context of the modeling approach we have adopted. Essentially, our simple treatment of private expectations significantly limits the range of policy experiments that can be sensibly conducted in our framework. As a result, fully integrating forecasting and policy analysis in CGE models like that presented here appears to require a sophisticated treatment of the nexus between private inflation expectations and regime shifts. We pursue this point further in section 4 .

\section{A CGE Model}

Variants of the so-called limited participation models suggested by Lucas (1990), Christiano (1991), and Fuerst (1992) have become increasingly popular vehicles for examining issues related to monetary policy. (Recent examples include Christiano and Eichenbaum [1992a, 1992b] and Coleman, Gilles, and Labadie [1994].) Limited participation in these contexts pertains to two essential model elements. First, monetary injections are asymmetric. Second, households' ability (or, implicitly, desire) to adjust cash balances is limited.

The specific variant that we adopt was developed in Carlstrom (1994) and has the following key features, many of which are common to other models of this sort: 
(a) Utility-maximizing households finance consumption expenditures out of liquid assets (base money in our formulation).

(b) In any given period (which we define to be one quarter), households must make their portfolio decision before the state of the world is revealed.

(c) In any given period, profit-maximizing firms purchase labor and investment goods. Investment purchases become operational with a two-period lag. Time $t$ investment commitments (which are irreversible) must be financed from retained earnings in (unequal) increments over time $t$ and $t+1$. Wage payments to labor are financed by one-period loans from a financial intermediary (bank).

(d) Money is introduced into the economy via financial intermediaries.

(e) Seigniorage from money creation is distributed to intermediaries in the form of lump-sum transfers, which are then redistributed to households (as claims on bank ownership).

(f) The monetary authority follows an interest-rate smoothing rule in determining the path of money growth.

The key characteristics of the equilibrium generated by the features just described (at least for the parameterizations of the model we study) are

(i) Monetary policy surprises have non-neutral effects on output in the short run. Furthermore, these shocks generate apparent "liquidity effects," or a temporary inverse relationship between money and nominal interest rates.

(ii) In the long run, Fisherian fundamentals determine the nominal interest rate, so that the steady-state nominal interest rate changes one for one with a change in the steady-state rate of inflation.

In the remainder of this section, we describe these elements in more detail and explain the procedures used in solving the model. 


\section{The Basic Structure}

\section{A. The Household}

Households derive utility from consumption, $C_{t}$, and leisure, $1-L_{t}$, to maximize discounted expected utility:

$$
E_{0} \sum_{t=0}^{\infty} \beta^{t} U\left(C_{t}, 1-L_{t}\right)
$$

Following Rogerson (1988) and Hansen (1985), we assume that labor is indivisible, so that agents either work or do not work. In addition, we assume the existence of complete markets that fully insure workers against unemployment. With separable utility, this implies that agents will have the same consumption whether or not they work. In this case, equation (1) specializes to

$$
U\left(C_{t}, 1-L_{t}\right)=\ln \left(C_{t}\right)+\gamma\left(1-L_{t}\right)
$$

Equation $\left(1^{\prime}\right)$ is maximized subject to

$$
P_{t} C_{t} \leq M_{t}-N_{t}+W_{t} L_{t}
$$

and

$$
M_{t+1} \leq R_{t} N_{t}+D_{t}+F_{t}+\left(M_{t}-N_{t}+W_{t} L_{t}-P_{t} C_{t}\right)
$$

The variables $M_{t}, P_{t}, C_{t}, W_{t}, L_{t}$, and $R_{t}$ are the time $t$ money holdings, nominal price level, consumption, nominal wage, hours worked, and gross nominal interest rate. Equation (2) is the cash-in-advance constraint, indicating that current money holdings finance nominal consumption expenditures. Money holdings consist of the worker's 
nominal wage earnings and the fraction of period $t$ money holdings left after depositing savings equal to $N_{t}$ dollars with the financial intermediary.

Equation (3) states that the sources of cash the household uses to carry into $t+1$ include interest on savings, plus dividend payments received from the intermediary $\left(D_{t}\right)$ and the firm $\left(F_{t}\right)$. Since the household is an atomistic part of the overall economy, dividend payments are outside its control and are equivalent to lump-sum payments. The sum in parentheses is the cash not spent after all consumption expenditures are made, which will be zero in equilibrium as long as the cash-in-advance constraint (equation [2]) is binding. Equation (2) will in fact hold with equality as long as the gross nominal interest rate is greater than the time discount rate (i.e., $R_{t}>\beta$ ).

The model economy is subject to two fundamental sources of uncertainty: a monetary (or interest-rate) shock and a technology shock (described below). Following Fuerst (1992), savings decisions $\left(N_{t}\right)$ are made before the realization of either shock. The labor supply choice, however, is made after the current state of the world is revealed.

\section{B. The Firm}

The economy consists of one representative (competitive) firm owned by the representative household. The firm produces a homogeneous good according to the following Cobb-Douglas production function:

$$
Y_{t}=f\left(K_{t}, e^{\mu t+z_{t}} H_{t}\right)=K_{t}^{\theta}\left(e^{\mu t+z_{t}} H_{t}\right)^{1-\theta}
$$

The parameter $\theta$ (where $0<\theta<1$ ) is capital's share in production, and $H_{t}$ is time $t$ labor demand. Labor-augmenting technical progress at time $t$ includes a deterministic drift 
term, $\mu_{t}$, and a random component, $z_{t}$, that evolves over time according to the following stochastic process:

$$
z_{t}=\rho_{z} z_{t-1}+\varepsilon_{t}
$$

where $0<\rho<1$ and $\varepsilon_{t}$ is a serially uncorrelated i.i.d. mean-zero, normally distributed shock.

At the beginning of period $t$, the firm must borrow from the financial intermediary to finance its nominal labor costs, $W_{t} H_{t}$. After production takes place, the firm pays off the loan and decides how much of its output it wishes to allocate toward investment, $I_{t}$.

Following Kydland and Prescott (1982), we assume that it takes time to build new capital. Specifically, new capital that comes on line in period $t+2$ is built in two phases over times $t$ and $t+1$. During each phase, a set fraction of the expenditure for this capital must be financed. At time $t$, during the initial phase of construction, the first installment $(\alpha)$ is paid, with the remainder $(1-\alpha)$ paid at time $t+1$. New capital projects initiated in period $t$ are defined to be $s_{2 t}$, where the subscript 2 indicates the time required before completion. Investment decisions are irreversible, so that firms must complete any investment projects begun in a previous period. This assumption implies $s_{2 t}=s_{1, t+1}$; i.e., projects that are two periods away from completion today are only one period from completion tomorrow.

The capital stock thus evolves according to the usual law of motion:

$$
K_{t+1}=(1-\delta) K_{t}+s_{1 t}^{\prime}
$$


where $\delta(0<\delta<1)$ is capital's depreciation rate. Investment, however, is defined by total expenditure, rather than by physical capital accumulation as given in equation (6). Thus, investment expenditures are given by

$$
I_{t}=\alpha s_{1 t}+(1-\alpha) s_{2 t}
$$

The firm uses the proceeds from selling the consumption good to retire its beginning-of-period labor loan, $R_{t} W_{t} H_{t}$. Since the firm is owned by the representative household, it maximizes

$$
E\left(\sum_{t=0}^{\infty} \beta^{t} \frac{U_{c, t+1}}{P_{t+1}} D_{t}\right)
$$

subject to (4), (5), (6), (7), and

$$
D_{t}=P_{t}\left[f\left(K_{t}, e^{\mu t+z_{t}} H_{t}\right)-I_{t}\right]-R_{t} W_{t} H_{t}
$$

C. The Financial Intermediary

The representative (competitive) financial intermediary is owned by the single representative household. In each period, the intermediary accepts household deposits, $N_{t}$, receives lump-sum transfers from the government equal to $M_{t+1}-M_{t}$ (the seigniorage the government receives from money creation), and loans $W_{t} H_{t}$ dollars to the firm. Because it receives a lump-sum transfer from the government in each period, the intermediary makes a profit, which it distributes to the household as a lump-sum payment. 
Similar to the firm, the intermediary seeks to maximize

$$
E\left(\sum_{t=0}^{\infty} \beta^{t} \frac{U_{c, t+1}}{P_{t+1}} F_{t}\right),
$$

subject to

$$
F_{t}=R_{t} W_{t} H_{t}-R_{t} N_{t}+\left(N_{t}+\left[M_{t+1}-M_{t}\right]-W_{t} H_{t}\right)
$$

Transfers from the government plus deposits by the household finance the firm's wage bill, so that the bond-market clearing condition is given by

$$
N_{t}+\left(M_{t+1}-M_{t}\right)=W_{t} H_{t}
$$

Thus, in equilibrium, the parenthetical term in equation (11) equals zero.

\section{The Government}

The government is the central bank, which supplies reserves to the banking sector. Letting $i_{t}\left(=R_{t}-1\right)$ denote the net nominal interest rate, reserves are supplied such that the deviation of the net nominal rate from its steady-state value follows the stochastic process

$$
\hat{i}_{t}=\rho_{r} \hat{i}_{t-1}+v_{t}
$$

where $v_{t}$ is an i.i.d. process with zero mean. (The overscore "hat" symbol indicates that a variable, the interest rate in this case, is expressed as a deviation from its steady-state value.) We assume that $0<\rho_{r}<1$, so that deviations of the interest rate from its steadystate value are persistent but stationary.

The reaction function in equation (13) differs from the standard specification, which is typically taken to be a first-order autoregressive process for money growth (see, 
for example, Fuerst [1992] and Christiano [1991]). However, except for the brief period between 1979 and 1982, the operational basis for U.S. monetary policy has been an interest-rate target. In the current environment especially, most FOMC decisions tend to be cast in terms of chosen federal funds targets. Thus, to provide policy advice at "FOMC frequencies," it is useful to have a model with an explicit interest-rate target.

Our interest-rate policy implies that money growth, which we denote by $G_{t} \equiv \frac{M_{t+1}}{M_{t}}$, is endogenous. In equilibrium, the (gross) steady-state interest rate and steady-state money growth rate are related by the condition

$$
G_{s s}=\beta R_{s s}
$$

Equation (14) states that, in equilibrium, the growth rate of money equals the growth rate of nominal consumption, a condition that follows from the cash-in-advance constraint. By choosing an interest-rate target to represent the monetary authority's reaction function, we face a well-known technical problem with respect to indeterminacy of equilibria. We turn now to a brief discussion of this and other issues related to solving the model.

\section{E. The Solution Approach}

Equilibrium in our model economy consists of a set of allocations such that households maximize utility, firms and intermediaries maximize utility-weighted profits, and market-clearing conditions in the loan market (equation [12]), the labor market

$$
L_{t}=H_{t}
$$


and the goods market

$$
C_{t}+I_{t}=f\left(K_{t}, e^{\mu t+z_{t}} H_{t}\right)
$$

are all satisfied.

Although the core problem is nonstationary, it is possible to obtain a stationary representation by normalizing relative to the aggregate money stock, $M_{t}$, and the deterministic growth trend, $\mu t$ (see Cooley and Prescott [1994] and Cooley and Hansen [1994] for details). As in Carlstrom (1994), equilibrium in the transformed model is found by solving a log-linear approximation of the original problem. ${ }^{2}$ Following Christiano (1991), the model's first-order conditions are linearized around its steady state, log-linear solutions for investment, labor, and portfolio allocations are posited, and the resulting decision rules are found using the method of undetermined coefficients. This solution technique explicitly yields expressions for deviations of output growth and inflation from their steady-state values as functions of the state variables $S_{t}=\left\{z_{t}, z_{t-1}, \hat{i}_{t}, \hat{i}_{t-1}, k_{t}, s_{1 t}\right\}$

By choosing to model policy in terms of a nominal interest-rate target, issues involving the indeterminacy of equilibria must be immediately confronted. As in the rational-expectations IS-LM framework examined by Sargent and Wallace (1975) and McCallum (1981), one aspect of the problem arises because monetary policy is incompletely specified. More precisely, a full specification of the monetary reaction function must involve specifying not only the interest-rate target, but also the initial

${ }^{2}$ We do not take the logs of variables already in percentage terms, i.e., the interest and inflation rates. 
money supply. ${ }^{3}$ However, as McCallum's examples suggest, there are still an infinite number of money growth rules that can support an interest-rate target. Unlike McCallum, however, the limited participation element of our model implies that any indeterminacy pertains to the solutions for real, as well as nominal, variables.

Because we confine ourselves to analyzing deviations around the steady state, arbitrary choices for initial conditions are of minimal importance. The much more important indeterminacy, which is independent of the initial condition problem, arises because there are an infinite number of stationary money growth rules that will support a given interest-rate target. In essence, nonuniqueness exists in our model because a money growth rule that includes arbitrary "sunspot" terms or extraneous information can support the chosen interest-rate target. In our analysis, we restrict ourselves to the money growth rule that is both stationary and devoid of sunspot variables. In other words, we follow McCallum and restrict ourselves to the money supply rule that can be supported with the minimal state variable set. A complete discussion of these issues can be found in Carlstrom and Fuerst (1994).

\section{Conditional Forecasting}

We turn now to the issue of conditional forecasting for output growth and inflation. Specifically, in this section we compare one-quarter- and one-year-ahead forecasts for GNP and CPI inflation generated by our CGE model, the Greenbook, and, for point of reference, an unconstrained bivariate VAR (with four lags of each variable).

\footnotetext{
3 Because the portfolio choice of agents in the limited participation setup is predetermined, it is more precisely $N_{0}$, and not the initial money supply, that must be specified.
} 
In addition, we consider a simple approach to forecasting inflation that relies on a naive application of the Fisher equation.

Before reporting the results, a few clarifying points are in order. First, a given Greenbook exercise is more precisely characterized as a "projection," as opposed to a forecast. In other words, although Greenbook estimates are made under particular assumptions about policy, those assumptions do not necessarily represent the Board staff's forecast of what policy actions will in fact be taken. Our model's estimates, on the other hand, more directly correspond to a true forecasting exercise in that we set the sequence of future policy actions on the basis of equation (13), which is the model's timeinvariant representation of the Fed's reaction function. ${ }^{4}$ This qualification duly noted, in what follows we will use the terms "forecast" and "projection" interchangeably.

Second, we note that the experiments, in one important regard, stack the deck against the Greenbook projections. Specifically, forecasts from both our model and the VAR are generated using final data that were unavailable to the Board staff at the time their estimates were made. ${ }^{5}$ We are essentially assuming that the data inputs into the CGE and VAR estimates are not subject to the obviously relevant measurement error that arises in Greenbook projections based on preliminary data.

Balancing this, on the other hand, is the fact that our CGE forecasts are made using data that would have been published only at the forecast date. To be more precise,

\footnotetext{
${ }^{4}$ Although there is no technical hurdle to performing projections with our model directly, such exercises would be of little interest without specific knowledge of the interest-rate paths upon which each Greenbook projection is based. We are investigating the possibility of obtaining information about the interest-rate assumptions used in the Greenbook data.

${ }^{5}$ In addition, the Greenbook forecasts apply to GNP, while forecasts from the other two models apply to GDP.
} 
recall that the model's solutions are a function of $S_{t}=\left\{z_{t}, z_{t-1}, \hat{i}_{t}, \hat{i}_{t-1}, k_{t}, s_{1 t}\right\}$. Because $s_{1 t}$ (the fraction of this quarter's investment expenditure that becomes operational capital in the subsequent quarter) is not directly observable, it is convenient to substitute from equation (6) (describing the evolution of the capital stock) to express the state vector as $S_{t}=\left\{z_{t}, z_{t-1}, \hat{i}_{t}, \hat{i}_{t-1}, k_{t}, k_{t+1}\right\}$. In constructing our forecasts, then, we simply extrapolate values for $z_{t}, k_{t+1}$, and $k_{t}$ from $t-1$ data and from the laws of motion in equations (5) and (6). We make no effort to improve the accuracy of the CGE projections by incorporating available real-time data that would enhance guesses for the elements of $S_{t}$ beyond these simple extrapolations. ${ }^{6}$

Finally, we recognize that the stochastic processes for both our theoretical model and the parameters of the VAR model are estimated using data for the entire sample and thus are based on information that was obviously unavailable at each of the forecast dates. Essentially, we are invoking the standard rational-expectations assumption that the model agents fully understand the distribution from which time series are drawn.

\section{Calibrating for Forecasting}

To the extent possible, our model is calibrated following the principles laid out in Kydland and Prescott (1994). Most of the parameters are standard in similar calibration exercises (see, for instance, Christiano [1991] and Cooley and Prescott [1994]): Capital's

\footnotetext{
6 It is possible, for example, that better estimates of time $t$ data on capital and the Solow residual could be constructed by replacing projections from the laws of motion with either monthly observations on industrial production and hours or updated forecasts for investment and output.
} 
share in production ( $\theta$ in equation [4]) is set to 0.36 . We choose the household's subjective time-discount factor ( $\beta$ in equation [1]) to be 0.988 in order to generate a steady-state capital-output ratio that matches the quarterly average found in the data over the 1983-1994 sample period (2.3). ${ }^{7}$ In a similar vein, we set the depreciation rate $(\delta$ in equation [6]) to 0.02 in order to match the observed investment-output ratio (about 0.11 ).

The parameter $\gamma$ in equation ( $\left.1^{\prime}\right)$ (the utility weight of leisure) is chosen so that in the steady state, households spend 31 percent of their nonsleeping hours working. The first-order stochastic process governing the (detrended) technology parameter $z$ was estimated from data over the period 1983-1994, giving an autoregressive parameter of $\rho_{z}=0.93$

Our operational definitions of the interest rate and money are, respectively, the federal funds rate and the monetary base. Inflation is measured by the growth rate of the CPI-U. In choosing the parameters describing monetary policy, we treat the period beginning in 1983 as a single monetary regime. Despite the abandonment of reserve targeting in October 1982, the logistical transition to interest-rate targeting was probably not fully phased in until 1984 (see Federal Reserve Bank of New York [1984, 1985]). Because of this, we estimate the autoregressive model for the federal funds rate using 1984:IQ as the initial observation. Based on this 1984-1994 (quarterly) sample, we $\operatorname{set} \rho_{r}=0.98$

The final parameter to be determined is $\alpha$ (the proportion of investment in time $t$ that must be financed contemporaneously). Setting $\alpha$ is made problematic by the lack of

7 Our capital measure includes private fixed capital and the stock of consumer durables. 
clear independent evidence for its value. Here, we follow Carlstrom (1994) and treat $\alpha$ as a free parameter chosen to "reasonably" match the variability of money growth found in the data. Furthermore, the value we choose, $\alpha=0.75$, results in procyclical equilibrium money growth, which is also in agreement with the data. ${ }^{8}$

\section{Forecast Comparisons}

We now turn to comparisons of the forecasting accuracy of our limited participation CGE model with those of the Greenbook and bivariate VAR models. We emphasize that these comparisons should not be construed as a "horse race" between competing forecasting models. The entire premise of this paper is that projections divorced from economic theory are of little value in the development of policy advice. Thus, our bias is to favor an explicit theoretical model over an atheoretic statistical model, even if the latter provides more accurate conditional forecasts. Having taken this position, however, we recognize that the analysis generated from highly stylized theoretical structures will be convincing only if connected to the data through the forecasting experiments inherent in the conduct of monetary policy as currently constructed. The forecast comparisons we report are therefore designed to aid in assessing the plausibility of our CGE model in this context.

Recall that both the inputs and solutions to the model are expressed as deviations from the steady state. Thus, in order to predict real-time movements in inflation and output growth, long-run average values for these variables must be specified. The steady-

\footnotetext{
${ }^{8}$ Setting $\alpha=0$ corresponds to Christiano's (1991) sluggish-capital model.
} 
state deviations generated by the model are then added to these long-run values to obtain the actual forecasts.

We set the steady-state fed funds rate to 7.4 percent and annual output growth to 2.6 percent, their respective average values from 1983 to 1994 . Given equation (14), the endogenous annual money growth rate to support this funds rate is 2.4 percent. Because this rate is less than the growth rate of output chosen for calibration, the implied steadystate inflation rate is slightly negative $\left(-0.2\right.$ percent annually, to be exact). ${ }^{9}$ Strict consistency with the model would require that we construct inflation forecasts relative to the endogenously determined steady-state value. Obviously, this value does not match the actual 1984-1994 sample mean of 3.7 percent. At least part of this discrepancy stems from changes in the velocity trend over the sample period. In obtaining our quantitative results, we simply make an ad hoc adjustment in assuming that deviations of the inflation rate are defined about a long-run value equal to the true sample mean. This procedure amounts to assuming that the model's failure to accurately predict the steady-state level of the inflation rate does not contaminate its ability to capture inflation dynamics at business cycle frequencies. ${ }^{10}$

The forecasting performance of the Greenbook, CGE, and VAR frameworks over the period from 1984:IQ through 1990:IVQ is reported in table 1. The terminal date of

9 Defining $r$ to be the real interest rate, the consumer's first-order condition (with $\log$ utility) is $c_{t+1} / c_{t}=\beta\left(1+r_{t}\right)$. With an annual discount factor of 0.9534 and annual consumption growth of 2.6 percent, the implied annual real interest rate is 7.6 percent. Since we impose a steady-state nominal rate of 7.4 percent, it follows directly from the Fisher equation that the steady-state inflation rate must be -0.2 percent. This value could obviously be altered by calibrating with an alternative discount factor or trend in output, but we have chosen to stick with the discipline imposed by the standard, well-defined calibration exercise. ${ }^{10}$ We are assuming that model agents and the forecaster know the sample means of interest rates, inflation rates, and growth rates during the 1983:IQ to 1994:IQ period. In that sense, we are not being completely fair in comparing our forecasts to those of the Greenbook. 
the forecasts is chosen to be the end of 1990 due to confidentiality restrictions on more recent Greenbook information.

The results in table 1 contain two notable features: 1) The forecast performance of the CGE model with respect to output growth is comparable to that of the Greenbook, but both do much worse than the atheoretic VAR, and 2) The ability of the Greenbook to forecast inflation is comparable to that of the VAR model, but the CGE model does substantially worse than either.

Because of our belief that price-level movements should be the primary concern of monetary policy, the relatively poor performance of the CGE model in forecasting inflation is the larger disappointment of these two observations. To provide some additional perspective, we also generated forecasts from a naive application of the Fisher equation by assuming a constant real funds rate (equal to the ex post real rate over the 1983-1994 sample) and interpreting changes in the average nominal rate as changes in one-quarter-ahead inflation forecasts. These "Fisher forecasts" generated a root-meansquared error of 0.205 and a mean absolute deviation of 1.88 , compared to 0.189 and 1.46 for the CGE model.

\section{A "Judgmental" Adjustment}

Although the CGE model does outperform the most naive forecasting approach, the advantage is hardly overwhelming. Some insight into why the model does not provide more accurate inflation forecasts can be found in figure 1, which plots the oneyear-ahead inflation forecasts from the model along with the actual realizations. 
Extending the sample through 1993 is especially useful, as the latter part of the period reveals a particularly stark failure of the model's predicted inflation outcomes.

Recall that the period from early 1992 through the end of 1993 --- a time frame over which the model does very poorly indeed -- was characterized by an initial period of persistent declines in the federal funds rate, followed by an extended period during which the rate stabilized near 3 percent. This behavior of the nominal interest rate becomes an input into the model through equation (13), the monetary reaction function. Specifically, these funds rate realizations in the data are fed into the model as deviations from a mean value of about 7 percent. The theoretical structure of the model implies that such large and persistent movements below the mean interest rate must be associated with a monetary policy that engineers an ongoing disinflation, just as figure 1 indicates.

Although this story pertains to very recent history, it is reasonable to conjecture that the failure revealing itself dramatically in the early 1990 s is present throughout the forecast period. Two explanations immediately suggest themselves as answers to why the model cannot track the interest rate without these counterfactual implications for the inflation rate. First, the extended sample period may be dominated by transitional dynamics from one steady state to another, so that the imposition of a single average interest rate to which the artificial economy ultimately tends creates a serious mismatch between the model and the data. However, simple ad hoc adjustments for this type of phenomenon -- such as treating the pre- and post-1991 periods as different monetary regimes with distinct mean funds rates and Fed reaction functions -- do not appreciably improve the model's forecasting ability. 
The other, more likely, explanation would appeal to a fundamental inability of the model's structure to capture the real interest-rate dynamics in the data. Such a failure can arise from the nominal side (because the limited participation setup does not capture the extent of monetary non-neutralities well), from the real side (because the basic one-sector growth framework does not generate sufficient persistence in the expected marginal productivity of capital), or from the inappropriateness of the rational-expectations assumption. $^{11}$

As an exploratory first step, we maintain the assumption that the nominal side of the model is correctly specified and assume that the cyclical behavior of the real interest rate is misspecified because of missing elements on the real side of the model. In other words, we assume that 1) the model's cash-in-advance/limited participation features adequately capture the key characteristics of actual money demand and financial intermediation, 2) the one-sector neoclassical growth features that are the foundation of the production side of the model cannot adequately capture the key dynamic characteristics of real intertemporal prices, and 3) the behavioral and technological additions that would help the model better match the cyclical pattern of the real interest rate are independent of money and financial intermediation. ${ }^{12}$

Under these admittedly strong maintained assumptions, we make the following ad hoc adjustment to the model: We first assume that the interest-rate process includes a

11 Admittedly, the distinction between the real and nominal sides of our model is, in some sense, arbitrary. Obviously, what we have called the nominal side affects real variables via the limited participation assumption, and the real side -- manifested in technology shocks and the basic propagation mechanisms generated by the basic technologies and preferences -- affects monetary dynamics due to the interest-rate target.

${ }_{12}$ The necessity of moving beyond one-sector frameworks has already been documented in other contexts. See, for example, Hansen and Prescott (1993) and McGratten, Rogerson, and Wright (1994). 
smooth deterministic trend, which we model as a four-quarter moving average. We then define the interest-rate shocks $(\hat{i})$ as deviations from this moving-average trend. Given that the Fed reaction function depends on these deviations, equation (13) is reestimated, yielding $\rho_{r}=0.79$. As shown by figure 2 , defining policy shocks relative to the movingaverage trend (as opposed to the sample mean) substantially alters both the magnitude and persistence of the interest-rate deviations.

Figure 3 illustrates the behavior of one-year-ahead inflation forecasts when the model is adjusted in this manner. As the picture clearly shows, the counterfactual prediction of a strong disinflationary trend subsequent to 1990 disappears. Furthermore, as evidenced in table 2 , the inflation forecasts generated by the CGE model become nearly identical to (and in some respects superior to) both the Greenbook and atheoretic VAR forecasts. The GDP projections of the CGE model are essentially unaffected by the moving-average adjustment and remain in the ballpark of the Greenbook forecasts.

The procedure just described is a judgmental adjustment to the model. It is not an internally consistent element of the framework in the sense that, as we take the model to the data, we use a moving conditional mean of the federal funds rate that does not arise from the model solution. However, because the forecasting exercise has an explicitly theoretical basis, our ad hoc adjustment -- which might be thought of as being analogous to so-called add factors in traditional large-scale statistical models -- comes in the form of a testable hypothesis. Specifically, the validity of our adjustment depends on the truth of our maintained assumption that real business cycle models can be constructed that yield the persistence in intertemporal prices implied by the moving-average process we have 
employed. We consider examining this hypothesis to be an important agenda item for further research along the lines introduced in this paper.

\section{Policy Analysis}

The forecasting exercises just described, while of independent interest, are discussed here in the context of generating policy advice. Operationally, this means using the model to generate projections conditioned on a policy baseline and then considering alternative paths generated by different policy actions. ${ }^{13}$

Recall our Fed policy function

$$
\hat{i}_{t}=\rho_{r} \hat{i}_{t-1}+v_{t}
$$

In the tradition following Lucas (1976), policy experiments are typically conceived of as alternative choices over the parameter $\rho_{r}$, or more generally, over the functional form of the reaction function. In other words, the idea of policy analysis conforms to the usual notion of a regime change. ${ }^{14}$

However, actual FOMC policy analysis as currently conducted is better characterized as involving experiments in which the form of equation (13) is maintained, and the policymaker "chooses" alternative paths for the error sequence $v_{t+j}$ for $j \geq 0$.

13 The typical Bluebook analysis does not conform neatly to this description. In most cases, the Bluebook simply provides narrow operational options tied to the annual money growth targets set as part of the Chairman's Humphrey-Hawkins testimony. More infrequently, the Bluebook provides long-run (three- to five-year) projections for inflation, output, and unemployment under different monetary growth and federal funds choices. These long-run strategy exercises most closely represent what we mean by policy analysis.

${ }^{14}$ Arguments about the consistency of rational expectations and policy analysis so conceived are an important part of this tradition. See, for example, Sargent (1984), Sims (1986), and Cooley, Leroy, and Raymon (1984). 
Performing analysis in this way obviously deviates from a strict rational-expectations construction, because policy is being chosen in a way that violates the process upon which private expectations are conditioned. However, as Leeper and Sims (1994) argue, this fact need not critically undermine this approach to generating policy advice. Given the difficult issues of credibility that accompany fundamental changes in the process governing monetary policy, useful information can be gleaned from examining a polar case in which private expectations of the policy regime are held constant, and policy actions are represented as a series of nonrandom "errors."

We view the issue as fundamentally empirical: Does the policy exercise described by Leeper and Sims yield quantitatively useful information, even though it does not conform to the strict logical structure of our CGE model? Unfortunately, the answer to this question appears to be "no," particularly if the relevant horizon is a period of longer than four to eight quarters.

Table 3 shows the results of an experiment in which, starting from the steady state, the federal funds rate path over a four-year horizon is chosen to support a 100-basispoint reduction in the rate of inflation, accomplished in two steps over two years. The experiments abstract from shocks to total factor productivity and are based on the version of the model that assumes, for quantitative purposes, a constant steady-state funds rate.

The resulting analysis looks fairly reasonable for the first few years, with "tighter" policy associated with rising interest rates and slightly lower output growth. However, the simulation results become increasingly difficult to swallow as the policy experiment is extended to longer horizons: By the end of the fourth year, our model associates a 2.7 
percent inflation rate with strongly negative output growth and a 37 percent federal funds rate.

The intuition for this result is fairly straightforward: Because the interest-rate rule is stationary, private expectations incorporate an eventual return to the steady-state inflation rate. To maintain an inflation rate below this level, the central bank must continually engineer positive surprises in the funds rate (surprises that private agents never recognize as part of deliberate policy). These surprises are, of course, responsible for the rising output losses seen in table 3.

These extreme results are driven by the failure to model explicitly what is in actuality a regime change. Absent frictions in the link between expectations and private actions that are more extreme than those inherent in our particular limited participation framework, the tight theoretical structure of our CGE model appears to require a more sophisticated treatment of either the Fed reaction function or the expectations formation process if the step from forecasting to policy analysis is to be satisfactorily bridged. ${ }^{15}$

\section{Conclusions}

The theme of this paper is that quantitative-theoretic models are capable of being called to the service of real-time forecasting and policy advice. We have intentionally chosen a relatively simple and highly abstract structure. Furthermore, our approach to the

15 In his 1986 article, Sims argued that policy analysis should be thought of as choosing among alternative realizations of some error process that is, in estimation, i.i.d mean zero by construction. This suggestion was made in the context of atheoretic VAR forecasting models. An important part of his argument was that the VAR structure may implicitly capture the nonlinearities associated with a nonzero probability of changes in the form of the Fed reaction function. Our experiments obviously do not address this claim. It remains an open question as to whether the phenomenon we confront arises in the much more tightly constructed VAR framework proposed by Leeper and Sims (1994). 
problem involves techniques that would be familiar to almost any graduate student. Despite this, when matched against the existing less structural approaches, our model does a remarkably good job of forecasting output and inflation.

However, we emphasize that equaling the forecasting performance of, say, the Greenbook, requires ad hoc adjustments to the model that do not arise from its theoretical structure. In particular, the model does not, of itself, generate empirically consistent real interest-rate and inflation behavior. We argue, however, that the judgmental "tricks" involved in improving the model's forecasting performance do not necessarily imply that the monetary side of our artificial economy is misspecified. In fact, we contend that our results suggest that even those primarily interested in the effects of monetary policy should take a keen interest in the further development of purely real business-cycle models.

The other clear lesson is that the use of quantitative-theoretic models for policy analysis in no way vitiates the need to build models that seriously address the issue of regime shifts. Although it is possible to examine regime shifts by assuming extreme credibility, such an analysis would, at least in our framework, be quite trivial: A perfectly credible regime shift would be approximately neutral. It would appear that sensible realtime policy advice along the lines we have suggested will ultimately require confronting the regime issue head on (see, for example, Cooley, Leroy, and Raymon [1984] and Prescott [1993]).

These problems are familiar ones and are equally applicable to the existing framework from which monetary policy advice is generated. Our criticism of the current 
policy-advice methodology is not that it is more susceptible to the thorny issues inherent in bringing economic reasoning to the policymaking table, but that it lacks the focal point of an explicit, widely understood theoretical structure, which compounds the difficulty of confronting these weaknesses. In presenting our CGE alternative, we have in mind the words of Robert Lucas (1987):

The chances that the model will survive ... criticism unscathed are negligible, but this seems to me exactly what explicit theory is for, that is, to lay bare the assumptions about behavior on which the model rests, to bring evidence to bear on these assumptions, to revise them when needed, and so on. (p. 47)

It is in "laying bare" the assumptions on which policy advice is given that, we believe, better monetary policy can be constructed, and it is in that spirit that our arguments are offered. 


\section{References}

Carlstrom, Charles T., "Interest-Rate Targeting and the Persistence of Monetary Innovations." manuscript, Federal Reserve Bank of Cleveland (March 1994).

Carlstrom, Charles T. and Timothy S. Fuerst, "Interest-Rate Rules as a Means of Eliminating Intertemporal Distortions." manuscript, Federal Reserve Bank of Cleveland (September 1994).

Christiano, Lawrence J., "Modeling the Liquidity Effect of a Money Shock." Quarterly Review, Federal Reserve Bank of Minneapolis (Winter 1991), 3-34.

Christiano, Lawrence J. and Martin Eichenbaum, "Liquidity Effects and the Monetary Transmission Mechanism." American Economic Review, 82 (May 1992a), 346-53.

Christiano, Lawrence J. and Martin Eichenbaum, "Liquidity Effects, Monetary Policy, and the Business Cycle." Discussion Paper No. 70, Institute for Empirical Macroeconomics, Federal Reserve Bank of Minneapolis (July 1992b).

Coleman, Wilbur John II, Christian Gilles, and Pamela Labadie, "Identifying Monetary Policy with a Model of the Federal Funds Market." manuscript, Duke University, 1994.

Cooley, Thomas F. and Gary D. Hansen, "Money and the Business Cycle." In Thomas F. Cooley, ed., Frontiers of Business Cycle Research, Princeton University Press: Princeton, NJ (1994), 175-216.

Cooley, Thomas F. and Edward C. Prescott, "Economic Growth and Business Cycles." In Thomas F. Cooley, ed., Frontiers of Business Cycle Research, Princeton University Press: Princeton, NJ (1994), 1-38.

Cooley, Thomas F., Stephen F. Leroy, and Neil Raymon, "Econometric Policy Evaluation: Note." American Economic Review, 74 (June 1984), 467-70.

Federal Reserve Bank of New York, "Monetary Policy and Open Market Operations in 1983." Quarterly Review, 9 (Spring 1984), 39-56.

Federal Reserve Bank of New York, "Monetary Policy and Open Market Operations in 1984." Quarterly Review, 10 (Spring 1985), 36-56.

Fuerst, Timothy S., "Liquidity, Loanable Funds, and Real Activity." Journal of Monetary Economics, 29 (1992), 3-24. 
Hansen, Gary D., "Indivisible Labor and the Business Cycle." Journal of Monetary Economics, 16 (1985), 309-27.

Hansen, Gary D. and Edward C. Prescott, "Did Technology Shocks Cause the 1990-1991 Recession?" American Economic Review, 83 (May 1993), 280-86.

Kydland, Finn E. and Edward C. Prescott, "Time to Build and Aggregate Fluctuations." Econometrica, 50 (1982), 1345-70.

Kydland, Finn E. and Edward C. Prescott, "The Computational Experiment: An Econometric Tool." Journal of Economic Perspectives, forthcoming; and Working Paper No. 9420, Federal Reserve Bank of Cleveland (December 1994).

Leeper, Eric M. and Christopher A. Sims, "Toward a Modern Macroeconomic Model Usable for Policy Analysis.” In Stanley Fischer and Julio J. Rotemberg, eds., NBER Macroeconomics Annual 1994, MIT Press: Cambridge, MA (1994), 81-117.

Lombra, Raymond and Michael Moran, "Policy Advice and Policymaking at the Federal Reserve." Carnegie-Rochester Conference Series on Public Policy, 13 (1980), 9-68.

Lucas, Robert E., Jr., "Econometric Policy Evaluation: A Critique." In K. Brunner and A. Meltzer, eds., The Phillips Curve and Labor Markets, Carnegie-Rochester Conference Series on Public Policy, 1 (1976), 19-46.

Lucas, Robert E., Jr., Models of Business Cycles, Basil-Blackwell: New York, 1987.

Lucas, Robert E., Jr., "Liquidity and Interest Rates." Journal of Economic Theory, 50 (1990), 237-64.

McCallum, Bennett T., "Price Level Determinacy with an Interest Rate Policy Rule and Rational Expectations." Journal of Monetary Economics, 8 (November 1981), 319-29.

McGratten, Ellen R., Richard Rogerson, and Randall Wright, "Estimating the Stochastic Growth Model with Household Production." manuscript, Federal Reserve Bank of Minneapolis (1994).

Poole, William, "The Making of Monetary Policy: Description and Analysis." Economic Inquiry, 13 (June 1975), 253-65.

Prescott, Edward C., "Effects of Monetary Policies: An Unexpected Finding." manuscript, Federal Reserve Bank of Minneapolis (February 1993). 
Rogerson, Richard, "Indivisible Labor, Lotteries, and Equilibrium." Journal of Monetary Economics, 21 (1988), 3-16.

Sargent, Thomas J., "Autoregressions, Expectations, and Advice." American Economic Review, 74 (May 1984), 408-15.

Sargent, Thomas J. and Neil Wallace, " 'Rational Expectations', the Optimal Monetary Instrument, and the Optimal Money Supply Rule." Journal of Political Economy, 83 (April 1975), 241-54.

Sims, Christopher A., "Are Forecasting Models Usable for Policy Analysis?" Quarterly Review, Federal Reserve Bank of Minneapolis (Winter 1986), 2-16. 
Table 1: Forecasting Performance of Alternative Models

\begin{tabular}{|l|c|c|c|}
\hline $\begin{array}{c}\text { Root-Mean-Squared } \\
\text { Errors }\end{array}$ & $\begin{array}{c}\text { Limited } \\
\text { Participation CGE } \\
\text { Model }\end{array}$ & Greenbook & $\begin{array}{c}\text { Bivariate VAR } \\
\text { Model }\end{array}$ \\
\hline $\begin{array}{l}\text { One-Quarter-Ahead } \\
\text { Inflation Forecasts }\end{array}$ & 0.189 & 0.148 & 0.130 \\
\hline $\begin{array}{l}\text { One-Year-Ahead } \\
\text { Inflation Forecasts }\end{array}$ & 0.188 & 0.110 & 0.095 \\
\hline $\begin{array}{l}\text { One-Quarter-Ahead } \\
\text { Output Growth Forecasts }\end{array}$ & 0.214 & 0.185 & 0.032 \\
\hline $\begin{array}{l}\text { One-Year-Ahead } \\
\text { Output Growth Forecasts }\end{array}$ & 0.144 & 0.127 & 0.032 \\
\hline Mean Absolute Errors & & & \\
\hline $\begin{array}{l}\text { One-Quarter-Ahead } \\
\text { Inflation Forecasts }\end{array}$ & 0.015 & 0.011 & 0.010 \\
\hline $\begin{array}{l}\text { One-Year-Ahead } \\
\text { Inflation Forecasts }\end{array}$ & 0.014 & 0.008 & 0.007 \\
\hline $\begin{array}{l}\text { One-Quarter-Ahead } \\
\text { Output Growth Forecasts }\end{array}$ & 0.015 & 0.016 & 0.002 \\
\hline $\begin{array}{l}\text { One-Year-Ahead } \\
\text { Output Growth Forecasts }\end{array}$ & 0.009 & & \\
\hline
\end{tabular}

Note: Sample period is 1984-1990. The CGE model forecasts are calculated using an average fed funds rate of 7.4 percent and a reaction function given by $\hat{i}_{t}=0.98 \hat{i}_{t-1}+v_{t}$. Output forecasts for the Greenbook refer to real GNP. Forecasts for the CGE and VAR models refer to real GDP.

Source: Authors' calculations. 
Table 2: Forecasting Performance of Alternative Models:

Adjusted CGE Model

\begin{tabular}{|l|c|c|c|}
\hline $\begin{array}{c}\text { Root-Mean-Squared } \\
\text { Errors }\end{array}$ & $\begin{array}{c}\text { Limited } \\
\text { Participation CGE } \\
\text { Model }\end{array}$ & Greenbook & $\begin{array}{c}\text { Bivariate VAR } \\
\text { Model }\end{array}$ \\
\hline $\begin{array}{l}\text { One-Quarter-Ahead } \\
\text { Inflation Forecasts }\end{array}$ & 0.133 & 0.148 & 0.130 \\
\hline $\begin{array}{l}\text { One-Year-Ahead } \\
\text { Inflation Forecasts }\end{array}$ & 0.097 & 0.110 & 0.095 \\
\hline $\begin{array}{l}\text { One-Quarter-Ahead } \\
\text { Output Growth Forecasts }\end{array}$ & 0.214 & 0.185 & 0.032 \\
\hline $\begin{array}{l}\text { One-Year-Ahead } \\
\text { Output Growth Forecasts }\end{array}$ & 0.149 & 0.127 & 0.032 \\
\hline $\begin{array}{l}\text { Mean Absolute Errors } \\
\text { One-Quarter-Ahead } \\
\text { Inflation Forecasts }\end{array}$ & 0.011 & 0.011 & 0.010 \\
\hline $\begin{array}{l}\text { One-Year-Ahead } \\
\text { Inflation Forecasts }\end{array}$ & 0.007 & 0.008 & 0.007 \\
\hline $\begin{array}{l}\text { One-Quarter-Ahead } \\
\text { Output Growth Forecasts }\end{array}$ & 0.015 & 0.016 & 0.002 \\
\hline $\begin{array}{l}\text { One-Year-Ahead } \\
\text { Output Growth Forecasts }\end{array}$ & 0.009 & & \\
\hline
\end{tabular}

Note: Sample period is 1984-1990. The CGE model forecasts are constructed using a four-quarter moving-average interest-rate trend and a reaction function given by $\hat{i}_{\imath}=0.79 \hat{i}_{t-1}+v_{t}$. Output forecasts for the Greenbook refer to real GNP. Forecasts for the CGE and VAR models refer to real GDP.

Source: Authors' calculations. 
Table 3: A Policy Experiment

\begin{tabular}{|l|c|c|c|c|c|}
\hline $\begin{array}{l}\text { Time } \\
\text { Period }\end{array}$ & 0 & 1 & 2 & 3 & 4 \\
\hline $\begin{array}{l}\text { Inflation } \\
\text { Rate }\end{array}$ & 3.7 & 3.2 & 2.7 & 2.7 & 2.7 \\
\hline $\begin{array}{l}\text { Nominal } \\
\text { Interest } \\
\text { Rate }\end{array}$ & 7.4 & 8.3 & 11.4 & 18.8 & 37.2 \\
\hline $\begin{array}{l}\text { Real } \\
\text { Output } \\
\text { Growth }\end{array}$ & 2.6 & 2.5 & 1.9 & 0.5 & -2.8 \\
\hline
\end{tabular}

Note: The experiments pertain to a policy of reducing realized rates of inflation from a steady-state value of 3.7 percent to 3.2 percent by the end of year one, to 2.7 percent by the end of year two, and to 2.7 percent thereafter. All entries are averages over the four quarters in each year.

Source: Authors' calculations. 
clevelandfed.org/research/workpaper/1995/wp9503.pdf
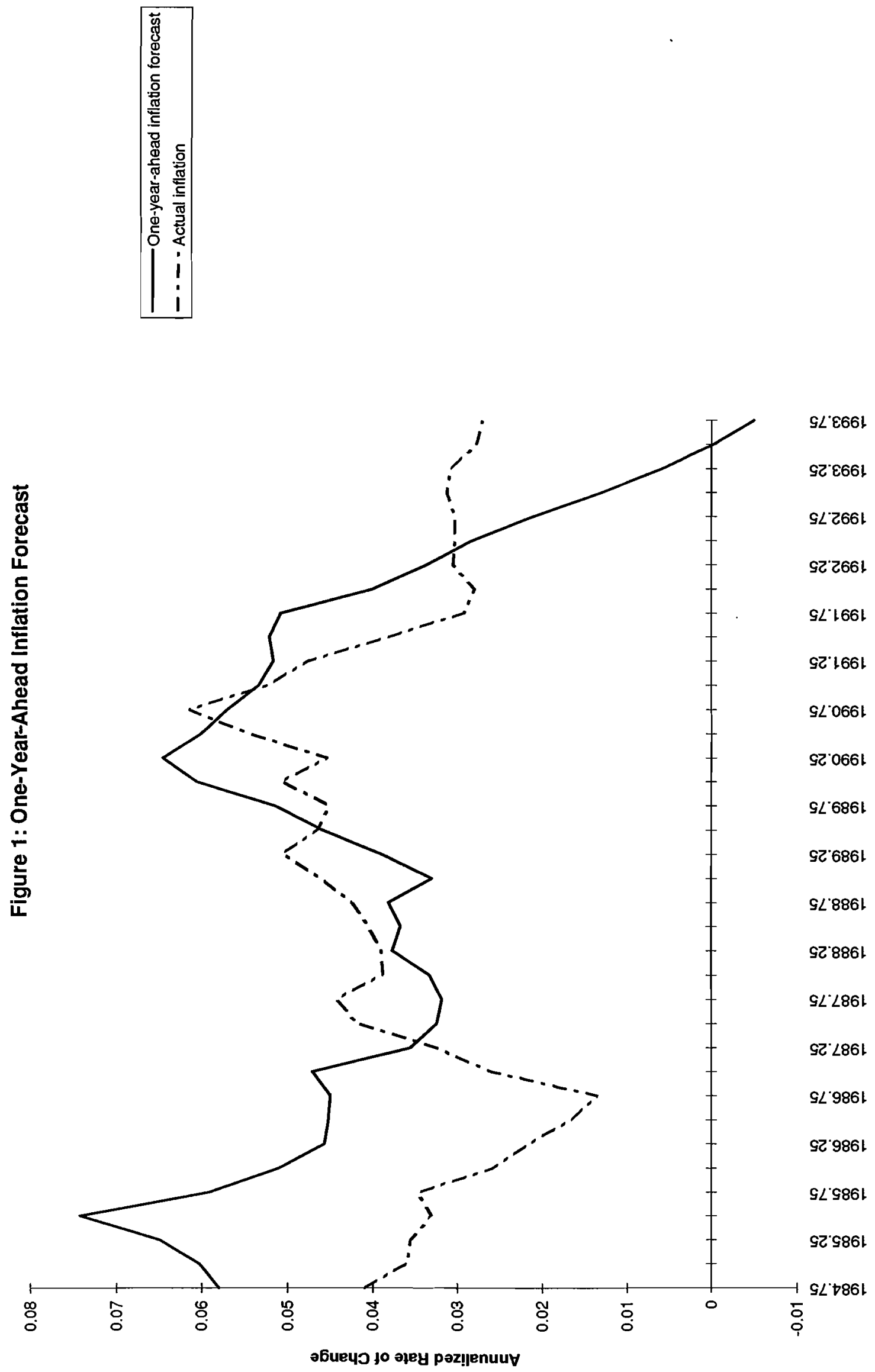

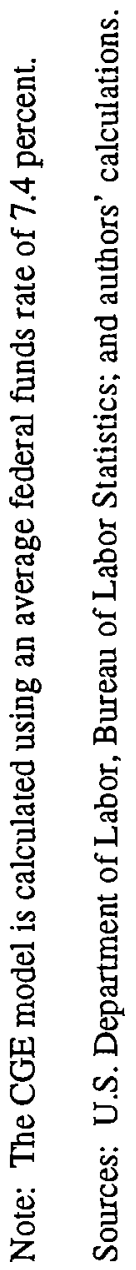




\section{Figure 2: Federal Funds Rate Deviations}

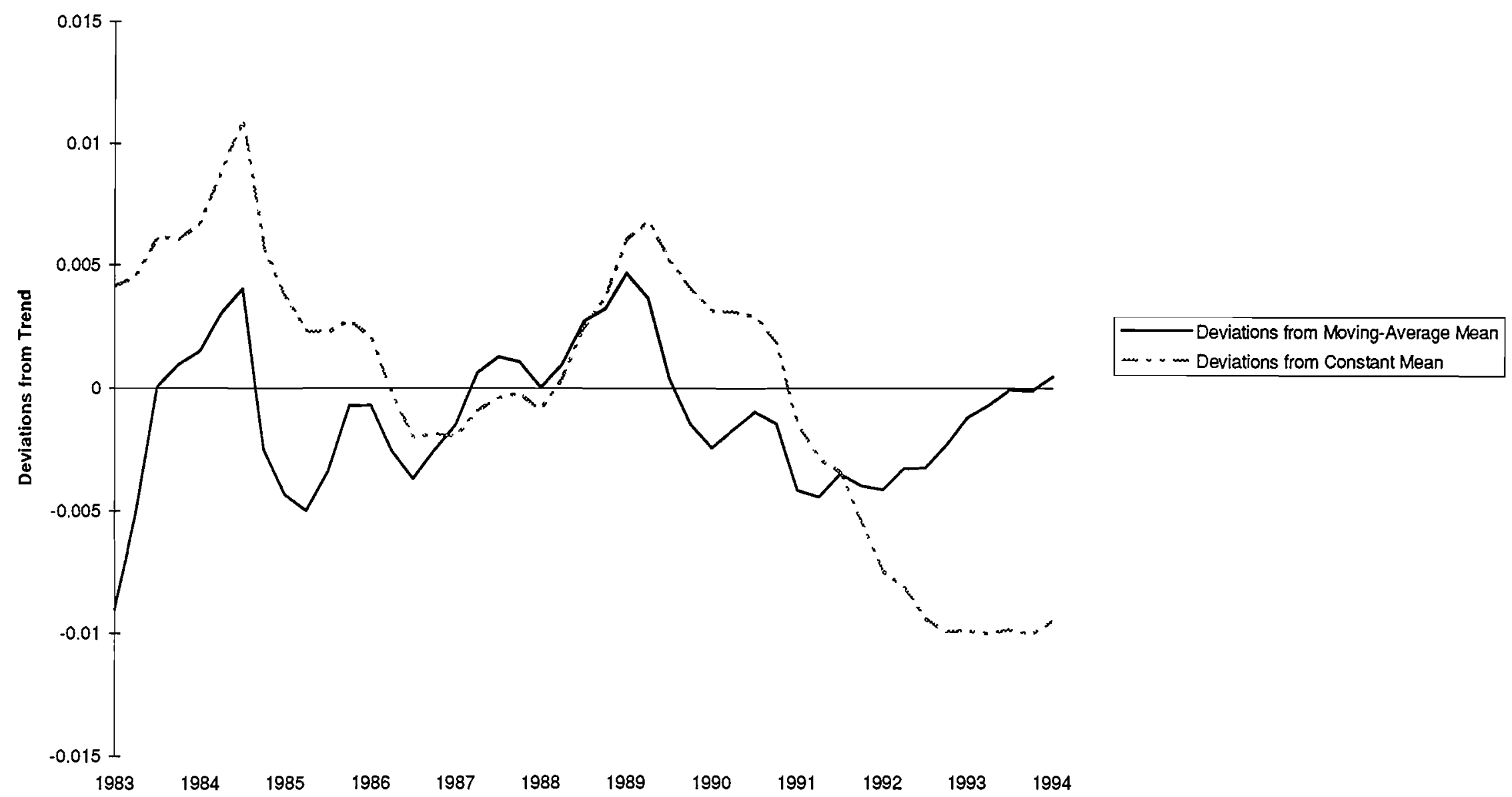

Source: Board of Governors of the Federal Reserve System. 
Figure 3: One-Year-Ahead Inflation Forecast

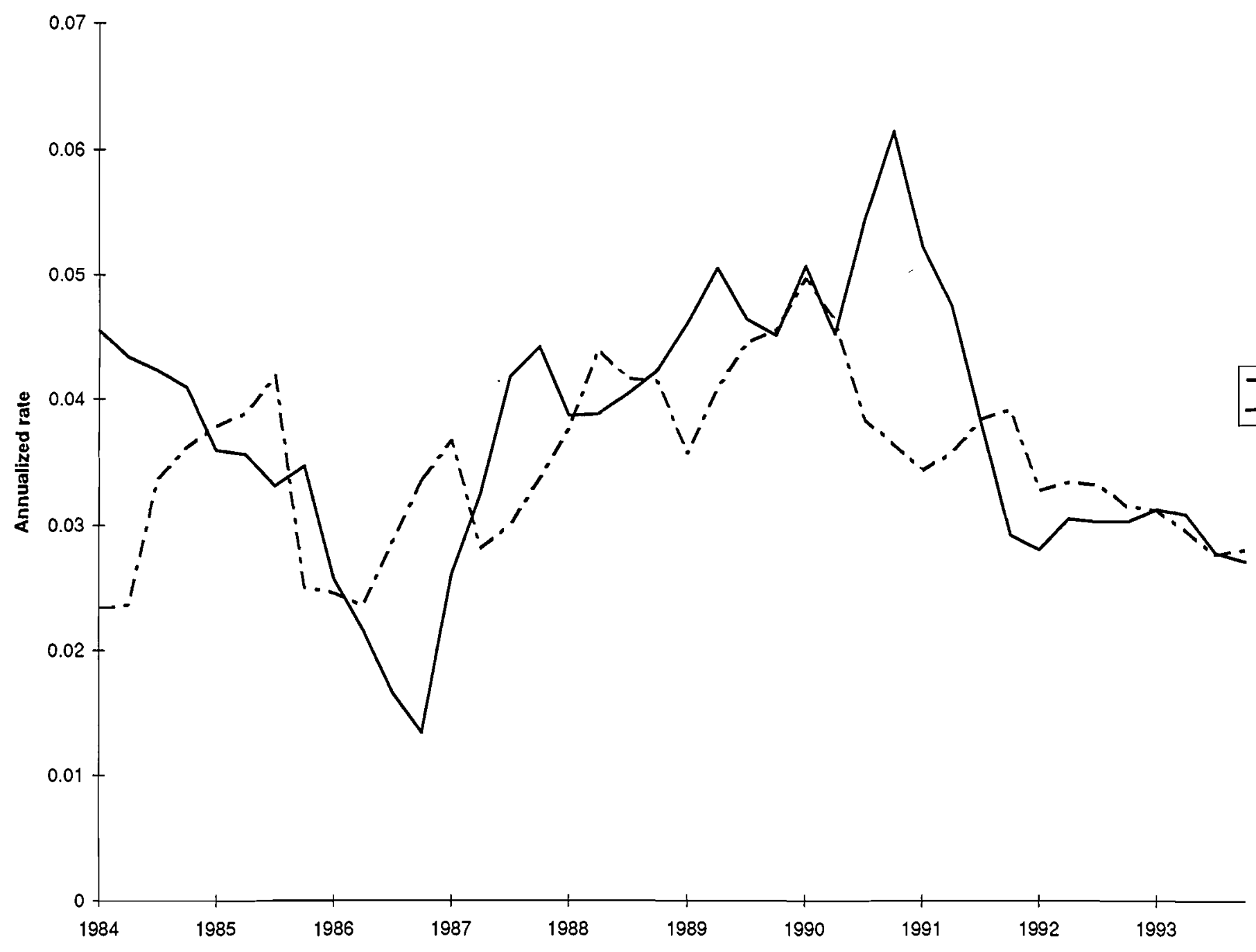

Note: The CGE model is calculated using a four-quarter moving average for the interest-rate trend.

Sources: U.S. Department of Labor, Bureau of Labor Statistics; and authors' calculations. 